Article

\title{
The Usage of Alternative Materials to Optimize Bus Frame Structure
}

\author{
Tautvydas Pravilonis ${ }^{1}$, Edgar Sokolovskij ${ }^{1}$, Artūras Kilikevičius ${ }^{2} \mathbb{D}$, Jonas Matijošius ${ }^{2, * \mathbb{D}}$ and \\ Kristina Kilikevičienè ${ }^{2}$ D \\ 1 Department of Automobile Engineering, Transport Engineering Faculty, \\ Vilnius Gediminas Technical University, J. Basanavičiaus g. 28, LT-03224 Vilnius, Lithuania; \\ tautvydas.pravilonis@vgtu.lt (T.P.); edgar.sokolovskij@vgtu.lt (E.S.) \\ 2 Institute of Mechanical Science, Vilnius Gediminas Technical University, J. Basanavičiaus g. 28, \\ LT-03224 Vilnius, Lithuania; arturas.kilikevicius@vgtu.lt (A.K.); kristina.kilikeviciene@vgtu.lt (K.K.) \\ * Correspondence: jonas.matijosius@vgtu.lt; Tel.: +370-684-04-169
}

Received: 20 May 2020; Accepted: 9 June 2020; Published: 15 June 2020

check for updates

\begin{abstract}
The strength and stiffness of the frame is one of the key indicators of vehicle structures. Insufficient stiffness causes vibration and noise, and is also less comfortable for both the passengers and the driver. Symmetry is required between the strength and comfort of the structural frame, which depends on vibration and noise. This article analyses the frame of the structure of a medium-sized passenger bus and its dynamic properties, when replacing materials of structural elements which do not affect the symmetry of the structure. The conducted theoretical and experimental modal analysis of the bus, allows for evaluating dynamic parameters and validating the theoretical model based on the experimental results. The optimization of the medium-sized passenger bus frame- by replacing the material of the ancillary frame elements with fiberglass-reveals that its dynamic characteristics change by up to $20 \%$, comparing the values of the first three resonant frequencies with those of the steel structure. The obtained results show that replacing the material of ancillary frame elements with fiberglass, while maintaining the symmetrical arrangement of the elements in the structure, does not change the safety characteristics of the structure, reducing the mass of the frame by $11 \%$, and shifting the coordinate of the centre of gravity vertically downwards, which is very important for stability, comfort and fuel consumption.
\end{abstract}

Keywords: bus frame; dynamic analysis; finite element method; alternative materials; mode

\section{Introduction}

Recently, high energy consumption and environmental pollution has increasingly raised global concern [1,2]. Anthropogenic greenhouse gas emissions have been the main cause of the earth's changing climate.

Road transport is one of the largest air pollutants, having an adverse effect on both the environment and human health [3-7].

Europe and many other countries are adopting new laws or regulations governing the development and sale of means of transport, in order to reduce $\mathrm{CO}_{2}$ emissions. Various institutions promote the use of electric vehicles to reduce fuel consumption and emissions. Many engineers are researching ways to increase battery capacity, in order to extend vehicle mileage. However, electric vehicles have one major problem--their battery weight and body structures make them quite heavy, reducing the mileage at which they can travel [8]. Therefore, it is important to not only develop electric vehicles, but also to reduce their weight. 
Reducing vehicle weight is one way to reduce fuel consumption and $\mathrm{CO}_{2}$ emissions. Accordingly, lighter, safer, more fuel-efficient and environmentally friendly vehicles are a priority for European authorities [9-12].

Lightweight materials may be used to reduce the weight of vehicles. They can be used both in the vehicle structure, and in interior or other components $[9,13,14]$.

Lightweight materials are an important technology that can reduce passenger vehicle fuel consumption by $6-8 \%$, with a $10 \%$ reduction in its weight. Even though the benefits of using lightweight materials are obvious, technology gaps mostly related to performance properties, connection to steel structures, and their price, prevent their widespread use in vehicle structures $[15,16]$.

Wenlong et al. [8] argues that lightweight materials could be widely used in the automotive industry, if their prices were the same as those of traditional materials.

As previously mentioned, the transport sector is one of the biggest polluters, and the increasing demand of society for mobility, also increases challenges related to traffic policymaking and vehicle manufacturing. The process of manufacturing new vehicles must adapt to increasingly stringent environmental requirements, but at the same time, manufacturers are obliged to ensure the basic safety and comfort requirements of vehicles [17-19].

Buses are one of the most popular types of vehicle, allowing people to travel both in cities and suburbs. Medium-sized buses, which give more freedom to both carriers and passengers, are more environmentally friendly and economical, and have been gaining popularity.

The frame accounts for $30 \%$ of the total weight of the bus in its overall structure. It is the most important element of the bus structure [17,20-22], and the part of the bus which bears the highest load [23].

The strength and stiffness of the bus frame are very important factors, having a significant impact on the generated vibrations and noise, respectively. This makes traveling less comfortable for both the passengers and the driver, and reduces the bus's stability and reliability during operation [24-27].

The structure of the bus body must be balanced, to ensure safety and comfort when riding on the bus. The body must be strong enough to withstand both normal loads and loads that form in accidents. Parameters of the bus body structure include stiffness, light weight, adaptability and welding possibilities. However, according to Guruprasad et al., [28], the conducted research identified certain inconsistencies in the technical parameters, i.e., the improvement of one parameter may make other parameters worse.

Despite the fact that this concept remains nearly unchanged, the total weight of a bus has increased by more than $25 \%$ over the last three decades. In order to resolve this problem, manufacturers have started using lightweight materials [8,17]. Rebaïne et al. [17] offers the use of aluminum, which would reduce the weight of the vehicle frame by $26.4 \%$. However, the use of fiberglass composites would allow a further reduction in the total bus weight. The stress values of composite materials do not exceed the limit values, and these materials are stronger. Therefore, Prasannapriya and Venugopal Rao [29], state that reducing the wall thickness and using composite materials, gives better results than the original model, which uses steel.

Buses, like all other vehicles, are also subject to certain safety requirements. According to Chirwa et al. [30], bus rollovers are most dangerous when a bus falls on a hard surface from a certain height. Such a rollover usually occurs when a bus moves in a curve subjected to centrifugal acceleration [31].

One of the basic safety requirements for a medium-sized bus, is the dynamic rollover test described in UN / ECE Regulation No. 66 [31,32]. A bus rollover is very dangerous, because it significantly deforms the roof and side walls, which in turn reduces the safe space to its minimum. A reduced safe space can hurt or even fatally injure passengers.

However, this dynamic rollover test is quite expensive and complex, as it requires both a prepared vehicle and a special rollover test bench $[33,34]$. Therefore, many manufacturers use the method of finite elements, to create models that perfectly simulate the behaviour of the actual structure $[31,33,35,36]$. 
However, assessing not only the strength of the structure, but also the comfort of passengers and the driver, is very important. The use of lightweight materials in vehicle structures can impair the strength of the vehicle body. The impaired stiffness of the vehicle body is one of the main reasons for its low modal frequencies [37]. Lower structural frequencies of modules causes strong flexible vibrations, and contributes to a less comfortable ride for the passengers [26,38].

The modal analysis was conducted with the aim to obtain structural resonance frequencies, and spatial characterization of vibration patterns, referred to as normal mode frequencies and shapes, respectively [39]. The identification of natural mode frequencies and shapes, is also important to avoid resonance and to improve dynamic parameters (noise and vibration) [40]. Furthermore, analysis of the natural vibration frequency and dynamic mode of the frame, is an important process to ensure both vehicle performance, and the safety and comfort of the passenger and driver [41-43]. The simulations made, allow Haryanto et al. [44] to state that the structural weight of a bus frame can be reduced by approximately $8 \%$, without changing its dynamic characteristics.

In order to ensure that the received simulation results are the same as those obtained during the field test, the building of a proper model, the selection of materials, and the comparison of results received from both the field and the digital model, are necessary.

In this analysis, both experimental and numerical dynamic tests of the model will be conducted, mainly aiming to determine and evaluate the properties of the bus structure, when steel is replaced by pultruded fiberglass pipes.

\section{Research Object and Experimental Modal Analysis}

Unlike large passenger buses, medium-sized buses are manufactured in two stages. A medium-sized passenger bus consists of two main elements: (a) the chassis, and (b) the passenger compartment. Usually, manufacturers of the second stage design the passenger compartment, and install it on the chassis.

This article examines a medium-sized passenger bus manufactured by the second stage manufacturer, "Altas Komercinis Transportas" (Lithuania). According to the technical (see Table 1) and economic characteristics, the IVECO 70C chassis was chosen as the basis for bus manufacturing, because this particular chassis is fully adapted to the manufacturing of buses, and all of the systems installed in the base have been certified in accordance with the safety requirements which buses are subject to. Furthermore, the IVECO 70C chassis contains the proper assembly of units necessary for a bus, i.e., the engine is in front of the driver's cab, and it has a rear-wheel drive.

Table 1. Technical vehicle characteristics.

\begin{tabular}{lr}
\hline Vehicle length, $\mathrm{mm}$ & 8480 \\
Chassis base, $\mathrm{mm}$ & 4750 \\
Vehicle width, $\mathrm{mm}$ & 2440 \\
Vehicle height, $\mathrm{mm}$ & 3100 \\
Total actual vehicle mass, $\mathrm{kg}$ & 6220 \\
Maximum technically permitted weight of a loaded vehicle, $\mathrm{kg}$ & 7200 \\
Number of seats (without a driver and a guide), pcs. & 29 \\
\hline
\end{tabular}

The main technical characteristics of the vehicle are presented in Table 1.

The IVECO 70C has a safety frame. It has fiberglass composite or tin body elements, and glass affixed thereto from the outside, with respectively installed interior trim elements inside. Figure 1a presents a general view of the bus.

Model validation. An experimental and theoretical modal analysis was performed to validate the theoretical model, aimed at choosing suitable bus frame materials. Having chosen the proper materials, the aim is to solve the optimization problem, in order to determine the optimal characteristics of the materials that make up the bus frame.

Experimental modal analysis. Figure 1 presents the test bench of the modal bus frame analysis. Bruel and Kjear equipment, which consists of data storage and processing equipment 3660D with 
a PC (Figure 1a, position 2), and accelerometers 8344, was used in the experimental modal analysis of the bus frame (Figure 1a, position 1). Measurements of the vibrations at 30 points of the bus frame (Figure $2 b$ ), were conducted in two directions (directions $Z$ and $X$ of Figure $1 b$ ), with 15 points on each side of the bus frame, respectively.

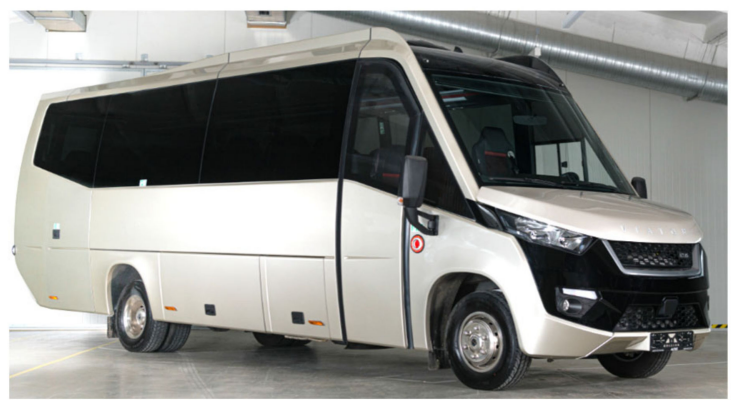

(a)

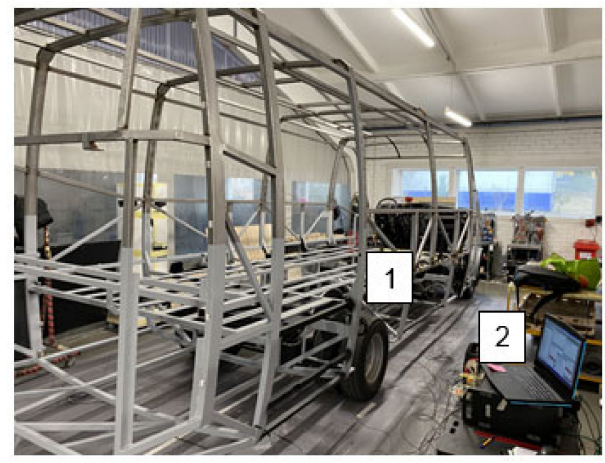

(b)

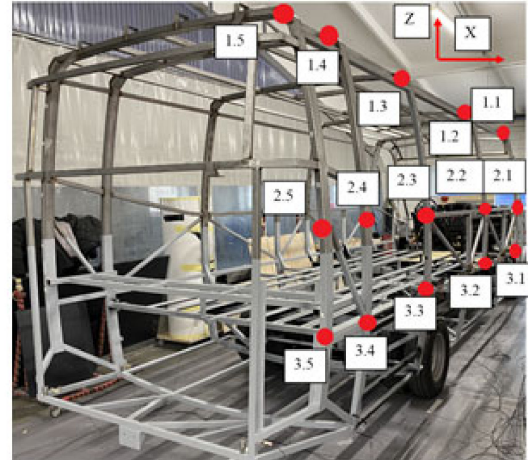

(c)

Figure 1. General view of the bus (a) and test bench of the modal bus frame analysis $(\mathbf{b}, \mathbf{c})$.
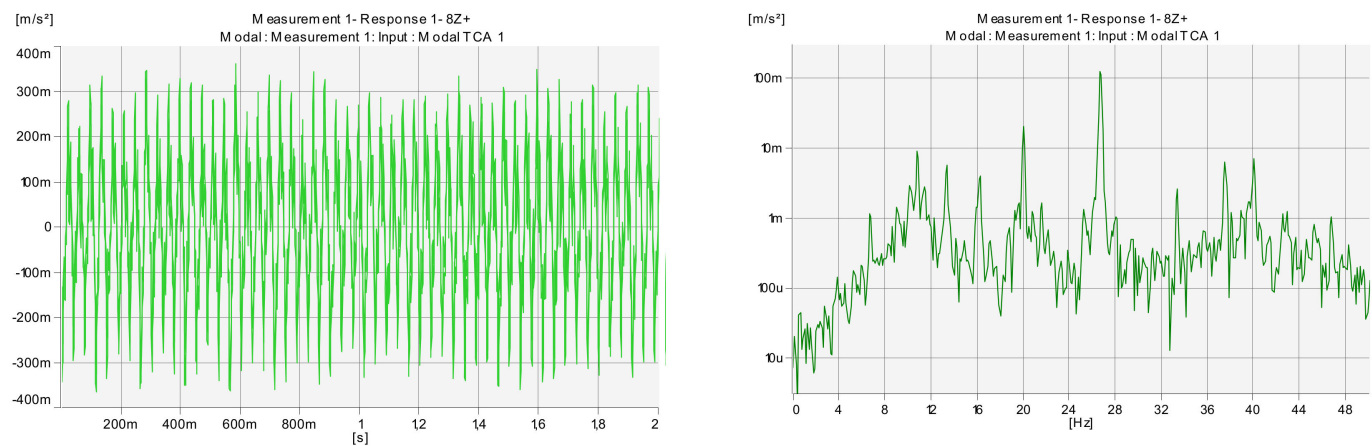

(a)
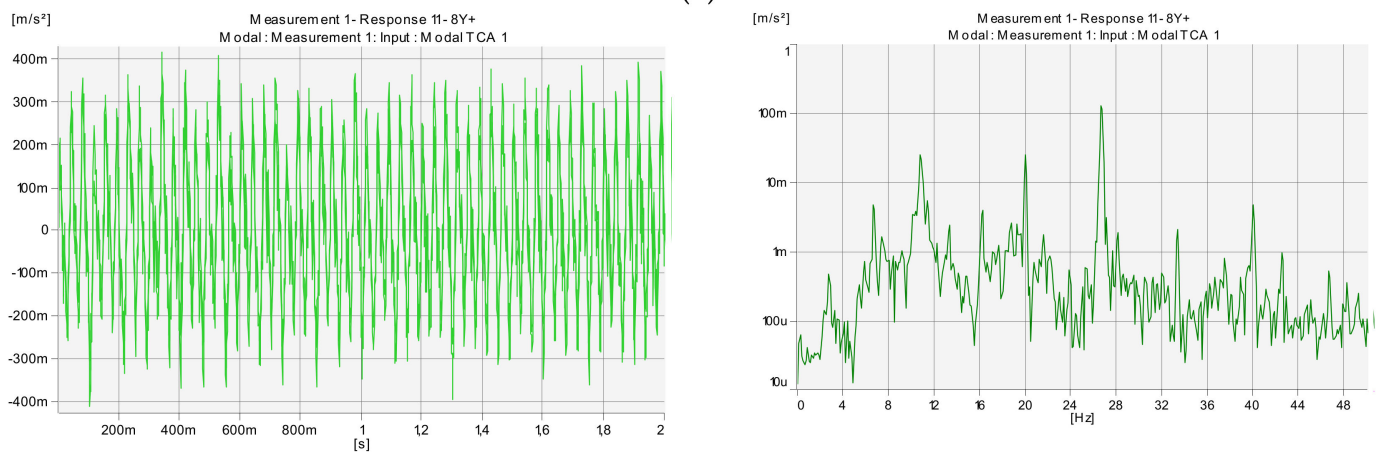

(b)

Figure 2. Histories of acceleration time, and frequency spectra of acceleration amplitudes of the middle point (Figure 1c 3.1 point) of the bus body, in vertical (a) and horizontal (b) directions. 
Operational modal analysis (OMA) was used in the experimental research. Forced excitation from the started engine, running at idle speed, was used in the modal bus frame analysis. Figure 2 presents the results of the vertical direction response of point 3.1 (Figure 1c) of the bus frame. The experimental and numerical natural frequencies of the bus body are presented in Table 2.

Table 2. Experimental and numerical natural frequencies of the bus body.

\begin{tabular}{cccc}
\hline \multirow{2}{*}{ Mode No } & \multicolumn{2}{c}{ Frequencies } & \multirow{2}{*}{$\Delta=f_{\text {FE }} / f^{E X P, \text { OMA }}$} \\
\cline { 2 - 3 } & $f^{E X P, O M A}, \mathbf{H z}$ & $f^{\text {FEM }, \mathrm{Hz}}$ & \\
\hline 1 & 6.512 & 6.711 & 1.031 \\
2 & 7.752 & 8.115 & 1.047 \\
3 & 9.841 & 9.912 & 0.721 \\
\hline
\end{tabular}

Figures 1-3, show the frame, which is made of steel 1.4003 (STALA400F). The properties of the steel are given in Table 3.

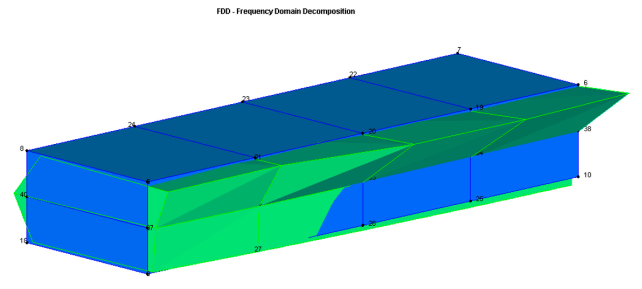

(a)

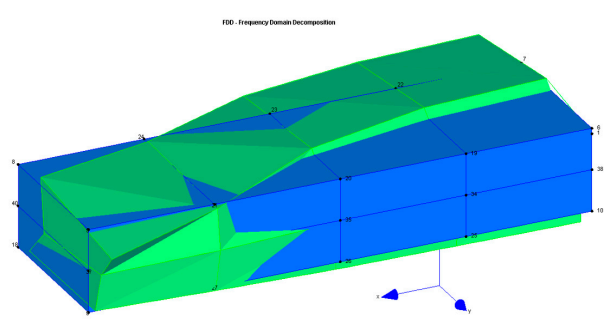

(c)

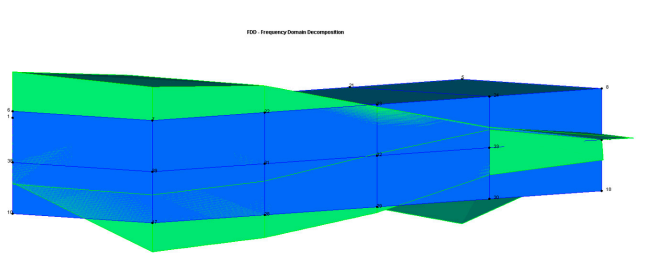

(e)

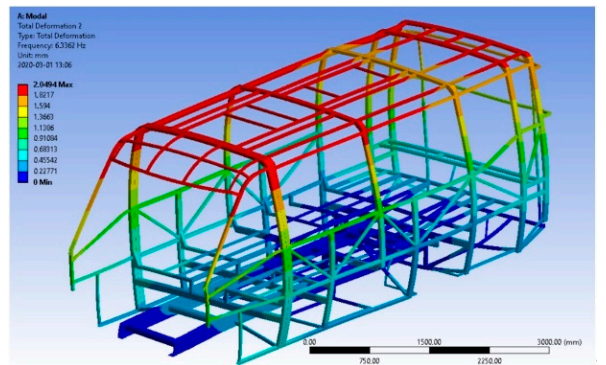

(b)

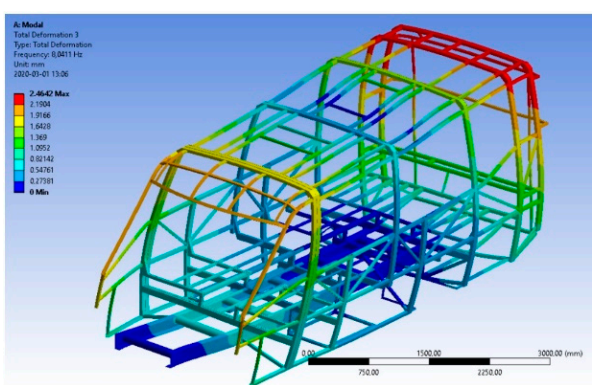

(d)

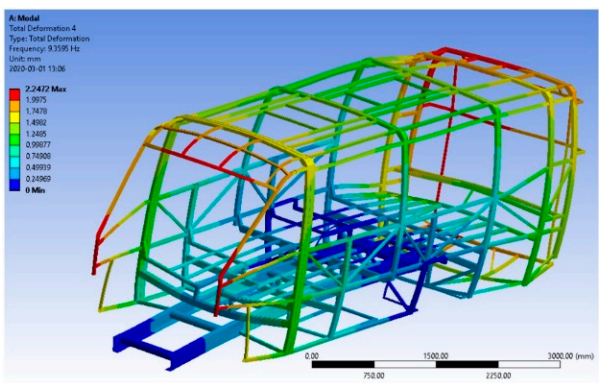

(f)

Figure 3. Results of OMA and FEM of the bus body: Steel construction first mode by OMA (a); Steel construction first mode by FEM (b); Steel construction second mode by OMA (c); Steel construction second mode by FEM (d); Steel construction third mode by OMA (e) and Steel construction third mode by FEM (f). 
Table 3. Experimental and numerical natural frequencies of the bus body.

\begin{tabular}{lcccc}
\hline & $\begin{array}{c}\text { Steel 1.4003 } \\
\text { (STALA400F) }\end{array}$ & \multicolumn{2}{c}{ GFRP (Vinyl Ester Resin) } \\
\hline \multicolumn{1}{c}{ Property } & - & \multicolumn{2}{c}{ Directionality } \\
& - & Longitudinal & Crosswise \\
\hline Density & $7700 \mathrm{~kg} / \mathrm{m}^{3}$ & \multicolumn{2}{c}{$2000 \mathrm{~kg} / \mathrm{m}^{3}$} \\
Tensile ultimate strength (MPa) & - & \multicolumn{2}{c}{364} \\
Compressive ultimate strength (MPa) & - & 364 & \\
Young's modulus (MPa) & 220,000 & 39,000 & 4875 \\
Poisson's ratio & 0.28 & 0.035 & 0.335 \\
Shear modulus (MPa) & - & 3358 & 3342 \\
\hline
\end{tabular}

When running at idle speed, the engine generates accelerations of up to $0.5 \mathrm{~m} / \mathrm{s}^{2}$ on the bus frame. The predominant acceleration amplitudes occur at the frequencies of 10.75, 20.00 and $26.63 \mathrm{~Hz}$; also, the analysis of the frequency ranging up to $50 \mathrm{~Hz}$, showed clearly expressed frequencies at 2.75, 6.625, $7.375,13.38,16.25,18.75,19.25,21.63,28.13,33.38,37.50,40.00$ and $42.50 \mathrm{~Hz}$.

In the virtual modal analysis carried out by Ansys 18.2 workbench software, upon using its complement "Modal", the conducted OMA showed three explicit modes presented in Figure 3a,c; and Figure $3 \mathrm{~b}, \mathrm{~d}$,f presents the results of the theoretical modal analysis conducted on the basis of the OMA, while Table 1 presents a comparison of the frequencies.

The received simulation results are very close to the experimental ones, with the discrepancy ranging from 0.72 to $4.7 \%$. Further calculations were made using the created bus body model. The construction of the bus body was optimized in the calculations, to make it lighter.

\section{Numerical Analysis of the Modified Bus Body}

Properties of the bus structure were changed by replacing steel with fiberglass, produced by way of pultrusion. In this work, the structure of the bus safety frame was designed using SolidWorks software, and Ansys was used for simulations. The steel in the safety frame of the bus was replaced with a fiberglass composite material, in order to reduce the total mass of the bus. Steel has a higher density than composite materials, so replacing it with composites makes the structure lighter.

A grid of finite elements was designed using the ANSYS 18.2 software (Figure 4). The fineness of the grid affects the accuracy of the result, and the speed of solving the problem; the finer the grid, the longer it takes to both design it and to solve the problem, and solving the problem requires a more powerful software. Table 3 presents the properties of materials used in the bus frame structure during the simulation.

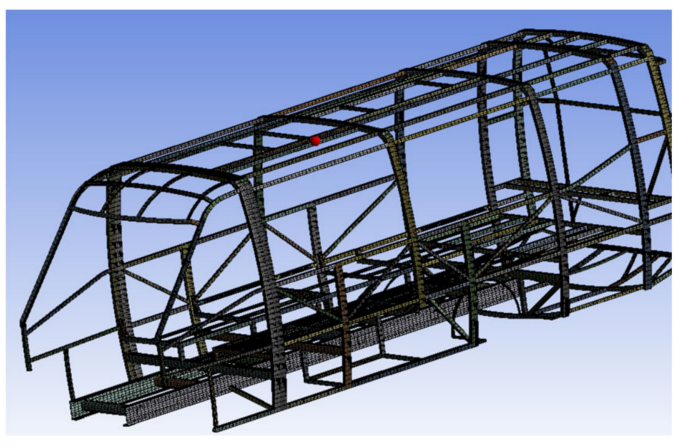

(a)

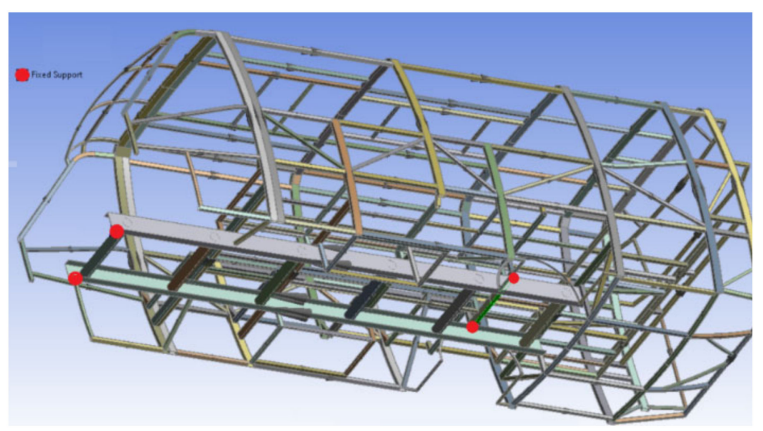

(b)

Figure 4. Finite element model of safety frame (a) and fixed support (b).

In addition, theoretical tests of three modifications were conducted. In these modifications, fiberglass was added to the bus frame structure, or it was used to entirely replace the steel contained in the frame. During the modifications, the symmetry of the structure was maintained, i.e., both 
the steel and the modified structure were intrinsically symmetrical. It can also be mentioned that in order to simplify the modelling in Ansys, the symmetry function could be used, using only half of the whole bus frame construction. However, in this particular case, the entire construction of the bus was analysed. The main parts of the frame that withstand loads (safety arcs), were replaced by fiberglass in the first modification; the roof and side materials (except for the safety arcs), were replaced by fiberglass in the second modification; and the entire frame material was replaced by fiberglass in the third modification. Modifications to the bus frame are shown in Figure 5. Table 4 presents the received results of the modal analysis.

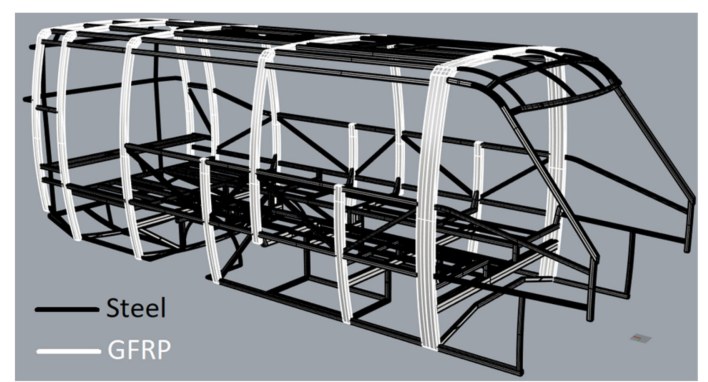

(a)

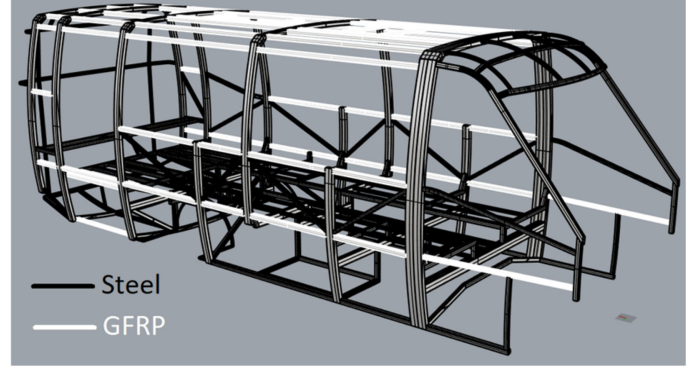

(b)

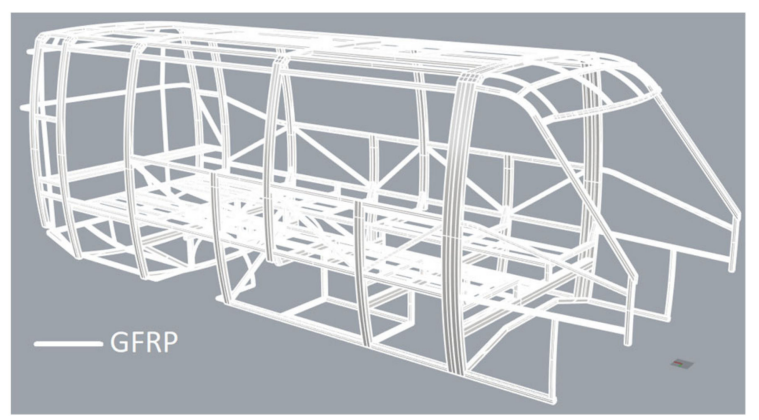

(c)

Figure 5. Modifications to the bus frame: (a) safety arcs replaced by fiberglass, (b) roof and side tubes (except for safety arcs) replaced by fiberglass and (c) the entire frame replaced by fiberglass.

Table 4. Results of numerical modal analysis of 4 modifications to the bus body.

\begin{tabular}{|c|c|c|c|c|c|c|c|}
\hline \multirow{4}{*}{ Mode No. } & \multicolumn{7}{|c|}{ Resonant Frequencies, $\mathrm{Hz}$ and the Change $\Delta=f_{F E s t e e l} / f_{F E}$} \\
\hline & \multirow{3}{*}{$\begin{array}{c}\text { Option1 } \\
\text { Steel } \\
\begin{array}{c}\text { Frequency, } \\
\text { Hz }\end{array}\end{array}$} & \multirow{2}{*}{\multicolumn{2}{|c|}{$\begin{array}{l}\text { Option2 } \\
\text { and Fiberglass } \\
\text { (Safety Arcs) }\end{array}$}} & \multicolumn{2}{|c|}{ Option 3} & \multicolumn{2}{|c|}{ Option 4} \\
\hline & & & & $\begin{array}{l}\text { Steel an } \\
\text { (Roof }\end{array}$ & $\begin{array}{l}\text { Fiberglass } \\
\text { d Sides) }\end{array}$ & \multicolumn{2}{|c|}{ Fiberglass } \\
\hline & & $\begin{array}{c}\text { Frequency, } \\
\mathbf{H z}\end{array}$ & $\begin{array}{c}\text { Change } \Delta= \\
f_{F E s t e e l} / f_{F E}\end{array}$ & $\begin{array}{c}\text { Frequency, } \\
\mathbf{H z}\end{array}$ & $\begin{array}{c}\text { Change } \Delta= \\
f_{F E s t e e l} / f_{F E}\end{array}$ & $\begin{array}{c}\text { Frequency, } \\
\mathbf{H z}\end{array}$ & $\begin{array}{c}\text { Change } \Delta= \\
f_{F E s t e e l} / f_{F E}\end{array}$ \\
\hline 1 & 6.711 & 4.789 & 1.401 & 6.009 & 1.117 & 2.654 & 2.529 \\
\hline 2 & 8.115 & 7.421 & 1.094 & 6.811 & 1.191 & 3.033 & 2.676 \\
\hline 3 & 9.912 & 9.421 & 1.052 & 8.785 & 1.128 & 3.692 & 2.685 \\
\hline 4 & 14.230 & 12.063 & 1.180 & 10.068 & 1.413 & 4.846 & 2.936 \\
\hline 5 & 14.863 & 12.173 & 1.221 & 11.442 & 1.299 & 4.962 & 2.995 \\
\hline
\end{tabular}

The received results (Table 4) showed that option 3, when the roof and side materials (except for the safety arcs) were replaced by fiberglass, rendered the smallest deviation compared to the steel structure. This modification was very close to option 4 , when the entire frame was made of steel (and that option is considered a benchmark). Similar results were also obtained with option 2, when the safety arc material was replaced by fiberglass. The frequency of option 1 changed the most, decreasing by 1.4 times-not good for the passengers' comfort. In this mode, the material of the safety arcs was also replaced by fiberglass, and additional tests should be carried out to ensure that this modification meets the resistance requirements, which the steel structure does. The assessment of option 4, when the entire frame structure was replaced by fiberglass, revealed poor results. The frequencies of the 
five modes being analysed ranged from 2.654 to $4.962 \mathrm{~Hz}$, meaning a poor level of comfort. A change in the mass, with different materials used and a shift in the center of gravity, were also assessed and presented in Table 5. The shift in the center of gravity is presented in direction $\mathrm{Z}$ only, because the change was very slight, up to $5 \mathrm{~mm}$, in all other directions.

Table 5. The mass of the frame during each modification.

\begin{tabular}{lllc}
\hline Option 1 & Option 2 & Option 3 & Option $\mathbf{4}$ \\
\hline Material steel & $\begin{array}{l}\text { Material steel and } \\
\text { fiberglass (safety bows) }\end{array}$ & $\begin{array}{l}\text { Material steel and fiberglass } \\
\text { (roof and sides) }\end{array}$ & Material fiberglass \\
\hline \multicolumn{4}{c}{ Construction mass, kg } \\
\hline 921.5 & 749.3 & 817.9 & 239.6 \\
\hline \multicolumn{4}{c}{ Coordinate of the center of gravity in direction Z (Figure 4a), $\mathbf{~ m m}$} \\
\hline
\end{tabular}

The assessment of the received results of the weight change, and a shift in the center of gravity of the structure, revealed that: the replacement of steel with fiberglass reduced the mass by $172.2 \mathrm{~kg}$, or $18.8 \%$ compared to the steel structure (when the safety arc material was also replaced by fiberglass); $103.6 \mathrm{~kg}$ or $11.24 \%$ (when the material of the roof and side was replaced by fiberglass); and $681.9 \mathrm{~kg}$ or $74.00 \%$ (when the whole frame was replaced by fiberglass). This is a significant reduction in mass, which would reduce fuel consumption of passenger vehicles by approximately $8 \%$ when replacing the material of the roof and sides by fiberglass, and approximately $15 \%$ when replacing the material of the safety arcs by fiberglass. The assessment of the option when the material of the whole frame was replaced by fiberglass, revealed that this would allow a significant reduction in fuel consumption, due to a $74 \%$ decline in the mass of the structure. The assessment of the change in the center of gravity in $\mathrm{Z}$ direction (Figure 4a), revealed that it shifts downwards by $111.37 \mathrm{~mm}$ when the material of the roof and sides was replaced by fiberglass, and $121.1 \mathrm{~mm}$ when the material of the safety arcs was replaced by fiberglass. These results show that the replacement of structural material would render a positive vehicle stability result, because of the center of gravity shifting closer to the ground.

\section{Conclusions}

This article analyses the dynamic properties of the passenger vehicle structure, showing the response of the structure to forced excitation.

The experimental resonant frequencies of the structure of the passenger bus frame received by the conducted theoretical and experimental research were $6.512,7.752$ and $9.841 \mathrm{~Hz}$, while the results of the developed theoretical model demonstrated good validation, with a discrepancy of $0.72-4.7 \%$.

The optimization of the passenger vehicle structure, when replacing the materials of the respective parts of the structure with fiberglass, allowed for the best dynamic parameters when the materials of the roof and sides were replaced with fiberglass. When it comes to mass reduction, the best result was obtained when replacing the whole frame structure with fiberglass, leading to a mass reduction of $74 \%$. However, an evaluation of the dynamic parameters revealed that the frequencies of the five modes being analysed-ranging from 2.654 to $4.962 \mathrm{~Hz}$ - was a very poor result in terms of passenger comfort. A shift of the center of gravity in the vertical direction $Z$, which directly affected vehicle stability, ranged from $111.37 \mathrm{~mm}$ to $121.1 \mathrm{~mm}$ when replacing the materials of the roof, the sides and the safety arcs of the structure. The conducted research revealed that regarding the optimisation of the passenger bus structure analysed in the article, the replacement of steel with fiberglass, rendered very impressive dynamic parameters of the structure, allowing for a reduction in mass, and a shift of the centre of gravity, in the vertical direction closer to the ground. 
Author Contributions: Conceptualization, T.P. and E.S.; methodology, A.K. and J.M.; software, K.K.; validation, T.P., E.S. and A.K.; formal analysis, J.M.; investigation, T.P. and A.K.; resources, E.S.; data curation, K.K; writing-original draft preparation, J.M., T.P. and A.K.; writing-review and editing, K.K. and E.S.; visualization, T.P. and A.K.; supervision, E.S.; project administration, J.M.; funding acquisition, K.K. All authors have read and agreed to the published version of the manuscript.

Funding: This research received no external funding.

Conflicts of Interest: The authors declare no conflict of interest.

\section{References}

1. Helms, H.; Lambrecht, U. LCA Case Studies The Potential Contribution of Light-Weighting to Reduce Transport Energy Consumption. Int. J. Life Cycle Assess 2007, 12, 58-64.

2. Maghrour Zefreh, M.; Torok, A. Theoretical Comparison of the Effects of Different Traffic Conditions on Urban Road Traffic Noise. J. Adv. Transp. 2018, 2018, 1-11. [CrossRef]

3. Younger, M.; Morrow-Almeida, H.R.; Vindigni, S.M.; Dannenberg, A.L. The Built Environment, Climate Change, and Health. Am. J. Prev. Med. 2008, 35, 517-526. [CrossRef] [PubMed]

4. Margaritis, D.; Anagnostopoulou, A.; Tromaras, A.; Boile, M. Electric commercial vehicles: Practical perspectives and future research directions. Res. Transp. Bus. Manag. 2016, 18, 4-10. [CrossRef]

5. Heutel, G.; Ruhm, C.J. Air Pollution and Procyclical Mortality. J. Assoc. Environ. Resour. Econ. 2016, 3, 667-706. [CrossRef]

6. Greenhouse Gas Emission Statistics-emission Inventories. Available online: https://ec.europa.eu/eurostat/ statistics-explained/pdfscache/1180.pdf (accessed on 18 May 2020).

7. Rimkus, A.; Pukalskas, S.; Matijošius, J.; Sokolovskij, E. Betterment of ecological parameters of a diesel engine using Brown's gas. J. Environ. Eng. Landsc. Manag. 2012, 21, 133-140. [CrossRef]

8. Wenlong, S.; Xiaokai, C.; Lu, W. Analysis of Energy Saving and Emission Reduction of Vehicles Using Light Weight Materials. Energy Procedia 2016, 88, 889-893. [CrossRef]

9. Yuce, C.; Karpat, F.; Yavuz, N.; Sendeniz, G. A Case Study: Designing for Sustainability and Reliability in an Automotive Seat Structure. Sustainability 2014, 6, 4608-4631. [CrossRef]

10. Kilikevičienè, K.; Kačianauskas, R.; Kilikevičius, A.; Maknickas, A.; Matijošius, J.; Rimkus, A.; Vainorius, D. Experimental investigation of acoustic agglomeration of diesel engine exhaust particles using new created acoustic chamber. Powder Technol. 2019, 360, 421-429. [CrossRef]

11. Gutarevych, Y.; Mateichyk, V.; Matijošius, J.; Rimkus, A.; Gritsuk, I.; Syrota, O.; Shuba, Y. Improving Fuel Economy of Spark Ignition Engines Applying the Combined Method of Power Regulation. Energies 2020, 13, 1076. [CrossRef]

12. Hunicz, J.; Matijošius, J.; Rimkus, A.; Kilikevičius, A.; Kordos, P.; Mikulski, M. Efficient hydrotreated vegetable oil combustion under partially premixed conditions with heavy exhaust gas recirculation. Fuel 2020, 268, 117350. [CrossRef]

13. Liu, Q.; Lin, Y.; Zong, Z.; Sun, G.; Li, Q. Lightweight design of carbon twill weave fabric composite body structure for electric vehicle. Compos. Struct. 2013, 97, 231-238. [CrossRef]

14. Duan, S.; Yang, X.; Tao, Y.; Mo, F.; Xiao, Z.; Wei, K. Experimental and numerical investigation of Long Glass Fiber Reinforced Polypropylene composite and application in automobile components. Transport 2017, 33, 1-9. [CrossRef]

15. Joost, W.J. Reducing Vehicle Weight and Improving U.S. Energy Efficiency Using Integrated Computational Materials Engineering. JOM 2012, 64, 1032-1038. [CrossRef]

16. Andrzejczak, K.; Młyńczak, M.; Selech, J. Poisson-distributed failures in the predicting of the cost of corrective maintenance. Eksploat. Niezawodn. Maint. Reliab. 2018, 20, 602-609. [CrossRef]

17. Rebaïne, F.; Bouazara, M.; Rahem, A.; St-Georges, L. Static and Vibration Analysis of an Aluminium and Steel Bus Frame. World J. Mech. 2018, 08, 112-135. [CrossRef]

18. Sathishkumar, P.; Wang, R.; Yang, L.; Thiyagarajan, J. Trajectory control for tire burst vehicle using the standalone and roll interconnected active suspensions with safety-comfort control strategy. Mech. Syst. Signal Process. 2020, 142, 106776. [CrossRef]

19. Mansfield, N.; Naddeo, A.; Frohriep, S.; Vink, P. Integrating and applying models of comfort. Appl. Ergon. 2020, 82, 102917. [CrossRef] 
20. Xu, L.; Xin, L.; Yu, Z.; Zhu, Z. Construction of a dynamic model for the interaction between the versatile tracks and a vehicle. Eng. Struct. 2020, 206, 110067. [CrossRef]

21. Xu, L.; Zhao, Y.; Li, Z.; Shi, C.; Yu, Z. Three-dimensional vehicle-ballasted track-subgrade interaction: Model construction and numerical analysis. Appl. Math. Model. 2020. [CrossRef]

22. Zhi, P.; Li, Y.; Chen, B.; Shi, S. Bounds-based structure reliability analysis of bogie frame under variable load cases. Eng. Fail. Anal. 2020, 114, 104541. [CrossRef]

23. Brumercik, F.; Lukac, M.; Caban, J.; Krzysiak, Z.; Glowacz, A. Comparison of Selected Parameters of a Planetary Gearbox with Involute and Convex-Concave Teeth Flank Profiles. Appl. Sci. 2020, 10, 1417. [CrossRef]

24. Yan, J.-B.; Zhang, W. Numerical analysis on steel-concrete-steel sandwich plates by damage plasticity model: From materials to structures. Constr. Build. Mater. 2017, 149, 801-815. [CrossRef]

25. Kilikevičlenè, K.; Skeivalas, J.; KilikevičIus, A.; PečEliūNas, R.; Bureika, G. The analysis of bus air spring condition influence upon the vibration signals at bus frame. Eksploat. Niezawodn. Maint. Reliab. 2015, 17, 463-469. [CrossRef]

26. Kilikevičius, A.; Kilikevičienè, K.; Matijošius, J. Investigation of Drivers' Comfort Factors Influencing Urban Traffic Safety. In Vision Zero for Sustainable Road Safety in Baltic Sea Region, Lecture Notes in Intelligent Transportation and Infrastructure; Varhelyi, A., Žuraulis, V., Prentkovskis, O., Eds.; Springer International Publishing: Berlin/Heidelberg, Germany, 2020; pp. 159-165. ISBN 978-3-030-22374-8.

27. Kilikevičius, A.; Kilikevičienè, K.; Fursenko, A.; Matijošius, J. The Analysis of Vibration Signals of Critical Points of the Bus Body Frame. Period. Polytech. Transp. Eng. 2020, 48, 296-304. [CrossRef]

28. Guruprasad, T.; Satish, B.; Maruhti, B.; Pramod, K.; Manjunatha, H. Bus body structural strength analysis through FEA. Int. J. Technol. Res. Eng. 2015, 2, 2494-2498.

29. Chinta, P.; Rao, L.V.V. A New Design and Analysis of BUS Body Structure. IOSR J. Mech. Civ. Eng. 2014, 11, 39-47. [CrossRef]

30. Chirwa, E.C.; Li, H.; Qian, P. Modelling a 32-seat bus and virtual testing for R66 compliance. Int. J. Crashworthiness 2015, 20, 200-209. [CrossRef]

31. Karliński, J.; Ptak, M.; Działak, P.; Rusiński, E. Strength analysis of bus superstructure according to Regulation No. 66 of UN/ECE. Arch. Civ. Mech. Eng. 2014, 14, 342-353. [CrossRef]

32. Gürsel, K.T.; Gürseslđ, S. Analysis of the Superstructure of a Designed Bus in Accordance with Regulations ECE R 66. Gazi Univ. J. Sci. 2010, 23, 71-80.

33. Gepner, B.; Bojanowski, C.; Kwasniewski, L.; Wekezer, J. Effectiveness of ECE R66 and FMVSS 220 standards in rollover crashworthiness assessment of paratransit buses. Int. J. Automot. Technol. 2014, 15, 581-591. [CrossRef]

34. Caban, J.; Rybicka, I. The Use of a Plate Conveyor for Transporting Aluminum Cans in the Food Industry. Adv. Sci. Technol.-Res. J. 2020, 14, 26-31. [CrossRef]

35. Na, J.; Wang, T.; Wu, C.; Yan, Y. A four-node membrane element model with bending modification for one-step algorithm for bus rollover impact. Eng. Comput. 2015, 32, 607-620. [CrossRef]

36. Buczaj, A.; Krzysiak, Z.; Pecyna, A.; Caban, J.; Brumercik, F. Safety during chemical transport of dangerous goods. Przem. Chem. 2019, 98, 1276-1280. [CrossRef]

37. Sun, Q.; Yuan, G.; Huang, Y.; Shu, Q.; Li, Q. Structural behavior of supported tubular bus structure in substations under seismic loading. Eng. Struct. 2018, 174, 861-872. [CrossRef]

38. Nagai, M.; Yoshida, H.; Tohtake, T.; Suzuki, Y. Coupled vibration of passenger and lightweight car-body in consideration of human-body biomechanics. Veh. Syst. Dyn. 2006, 44, 601-611. [CrossRef]

39. Kowarska, I.; Korta, J.; Kuczek, K.; Uhl, T. Fully Equipped Dynamic Model of a Bus. Shock Vib. 2014, 2014, 1-9. [CrossRef]

40. Gauchía, A.; Olmeda, E.; Boada, M.J.L.; Boada, B.L.; Díaz, V. Methodology for bus structure torsion stiffness and natural vibration frequency prediction based on a dimensional analysis approach. Int. J. Automot. Technol. 2014, 15, 451-461. [CrossRef]

41. Liu, T.; Tian, Y.; Xue, Q.; Wei, Z.; Qian, Y.; Feng, Y. An advanced three-way factor analysis model (SDABB model) for size-resolved PM source apportionment constrained by size distribution of chemical species in source profiles. Environ. Pollut. 2018, 242, 1606-1615. [CrossRef]

42. Zöldy, M. Automotive Industry Solutions in Response to European Legislative Emission Regulation Challenge. Moksl. Liet. Ateitis 2009, 1, 33-40. [CrossRef] 
43. Deng, L.; Wang, W.; Cai, C.S. Effect of pavement maintenance cycle on the fatigue reliability of simply-supported steel I-girder bridges under dynamic vehicle loading. Eng. Struct. 2017, 133, 124-132. [CrossRef]

44. Haryanto, I.; Raharjo, F.A.; Kurdi, O.; Haryadi, G.D. Optimization of Bus Body Frame Structure for Weight Minimizing with Constraint of Natural Frequency using Adaptive Single-Objective Method. Int. J. Sustain. Transp. Technol. 2018, 1, 9-14. [CrossRef] 